2. Okubo K, Okamoto T, Isobe J, Ueno Y. Rupture of a chronic expanding hematoma of the thorax into lung parenchyma. J Thorac Cardiovasc Surg. 2004;127:1838-40. doi:10.1016/j.jtcvs.2004.08.008

\section{Isolated mediastinal skip metastasis in lung cancer: Is it real N2 disease?} To the Editor:

I read with great interest the study by Keller and colleagues ${ }^{1}$ for the Eastern Cooperative Oncology Group titled "Prolonged Survival in Patients With Resected Non-Small Lung Cancer and Single-Level N2 Disease," published in the July 2004 issue of the Journal. The better prognosis for single-level N2 disease than for multiple N2 station involvement is a relatively old concept. Keller and colleagues ${ }^{1}$ correctly reported that several previous studies showed a better clinical outcome of patients with mediastinal skip metastasis than for patients with metastases also in the hilar nodes. The results of the Eastern Cooperative Oncology Group's trial indicated that this advantage is limited to upper lobe tumors, especially to the left upper lobe. The authors stated that "the reason for improved survival remains unclear, although patients with skip metastases may have true regional disease."

I would suggest that the scientific explanation of such results may be found in the recent studies on the sentinel node in non-small cell lung cancer. The sentinel node should be the first site of metastatic involvement, because it is the first lymph node that receives afferent lymphatic drainage from a primary tumor. The sentinel lymph node is located in the mediastinum in as many as 35\% of patients; mediastinal sentinel nodes are generally found from upper lobe tumors, with the highest incidence in the left upper lobe. ${ }^{2-6}$ Furthermore, such data are not new. An excellent anatomic French study published in the Journal in 1989 demonstrated that the direct lymphatic drainage of lung segments to the mediastinal nodes is quite common for the upper lobes. ${ }^{7}$ All such reports indicate that isolated involvement of mediastinal sentinel nodes could be considered in the group of $\mathrm{N} 1$ disease. It is not surprising that a large, cooperative, randomized, prospective trial led to such conclusions.

In conclusion, I think that the current knowledge on the anatomic pathway of the pulmonary lymphatic drainage indicates that the TNM classification regarding $\mathrm{N}$ status is quite rough. The Eastern Cooperative Oncology Group's trial is another important confirmation that stage IIIa nonsmall cell lung cancer represents an extremely heterogeneous disease stage, open to future staging revision.

Francesco Puma, MD, Chief of General Thoracic Surgery Azienda Ospedaliera S. Maria University of Perugia Medical School

Terni, Italy

\section{References}

1. Keller SM, Vangel MG, Wagner H, Schiller $\mathrm{JH}$, Herskovic A, Komaki R, et al. Prolonged survival in patients with resected non-small lung cancer and single-level N2 disease. J Thorac Cardiovasc Surg. 2004;128:130-7.

2. Little AG, DeHoyos A, Kirgan DM, Arcomano TR, Murray KD. Intraoperative lymphatic mapping for non-small cell lung cancer: the sentinel node technique. J Thorac Cardiovasc Surg. 1999;117:220-4.

3. Liptay MJ, Grondin SC, Fry WA, Pozdol C, Carson D, Knop C, et al. Intraoperative sentinel lymph node mapping in non-small-cell lung cancer improves detection of micrometastases. J Clin Oncol. 2002:20;1984-8.

4. Nomori $H$, Horio $H$, Naruke $T$, Orikasa $H$, Yamazaki K, Suemasu K. Use of technetium$99 \mathrm{~m}$ tin colloid for sentinel node identification in non-small cell lung cancer. $J$ Thorac Cardiovasc Surg. 2002;124:486-92.

5. Schmidt FE, Woltering EA, Webb WR, Garcia OM, Cohen JE, Rozans MH. Sentinel nodal assessment in patients with carcinoma of the lung. Ann Thorac Surg. 2002;74:870-5.

6. Sugi K, Kaneda Y, Sudoh M, Sakano H, Hamano K. Effect of radioisotope sentinel node mapping in patients with cT1 N0 M0 lung cancer. $J$ Thorac Cardiovasc Surg. 2003;126:568-73.

7. Riquet M, Hidden G, Debesse B. Direct lymphatic drainage of lung segments to the mediastinal nodes: an anatomic study on 260 adults. J Thorac Cardiovasc Surg. 1989;97: 623-32.

doi:10.1016/j.jtcvs.2004.08.029

\section{Studies of fetal cardiac bypass \\ To the Editor:}

In their elegant studies of fetal cardiopulmonary bypass $(\mathrm{CPB})$, Carotti and colleagues ${ }^{1}$ use time-dated pregnant sheep of 120 to 130 days' gestation. Indeed, in all published studies, the preferred animals for studying fetal CPB have been near-term fetal sheep (mean, approximately 126 days' gestation; term, 148 days' gestation). However, this age does not agree with the now-accepted window for effective fetal therapy in the clinical setting: 21 to 29 weeks' human gestation. Therefore we propose that all investigators conduct future fetal CPB studies at clinically relevant gestational ages (83-112 days' gestation in sheep; see below).

This is of great import when considering the vast changes taking place in the uteroplacental and umbilical-placental vascular beds during pregnancy. For example, the uterine weight, uterine blood flow (UBF), and UBF per gram of uterine weight increase significantly from 90 days onward. Indeed, this final phase in the growth of UBF is exponential and associated with a 3-fold increase in fetal weight that occurs after 110 days in sheep and beyond 30 weeks in human subjects. ${ }^{2}$ Similarly, blood flow distribution during this period changes substantially; nearly half the UBF is diverted away from endometrium-myometrium to the placenta. These changes reflect significant alterations in placental vascular resistance, which affect studies of fetal CPB. Finally, similar gestational differences in physiology affect other experimental features, such as fetal responses to steroids. ${ }^{3}$

We would like to caution investigators, however, against using direct gestational equivalence (human 280 days $=$ sheep 148 days). Differences in fetal growth rates between species can lead to large errors when assuming direct equivalence, as we discovered during our research involving earlygestation lambs. Therefore, we developed an equation to successfully translate gestational equivalence between species on the basis of previous studies of sheep ${ }^{4}$ and human ${ }^{5}$ embryos that have established the gestational age for completion of specific Carnegie stages of development. We translated these stages into developmental equivalence at specific times during gestation. Using the age for each species at equivalent Carnegie stages and assuming full-term pregnancy, we derived a seconddegree polynomial equation:

Sheep gestation day $=-0.003 \times$ Human gestation $d_{a y}^{2}+0.6296-$ Human gestation day,

with a correlation coefficient $\left(R^{2}\right)$ equal to 0.9973 .

Comparing our developmentally based gestational age with that determined by direct equivalence reveals a difference as large as $14 \%$, which can significantly affect experimental design. For example, a 5-day 
difference in gestational age (eg, 78 vs 83 days for 21 weeks' human gestation) can lead to a difference of $180 \mathrm{~g}$ for a singleton fetus (720 vs $900 \mathrm{~g}$ ). These weight differences can have substantial implications in surgical technique. At the latter part of the range (29 weeks' human gestation), when the fetus is growing more rapidly, the difference is even larger; for a 107-day (2.23 $\mathrm{kg}$ ) versus 112-day $(2.71 \mathrm{~kg})$ singleton fetus, the difference is about $500 \mathrm{~g}$. Finally, calculations based on these variations can also greatly influence results. For example, calculation of satisfactory fetal CPB flow rates (on the basis of milliliters per kilogram per hour) can be substantially different and potentially inadequate when using the wrong gestational age and fetal weight.

Joseph A. Sedgwick, MD

Pirooz Eghtesady, MD, PhD

Department of Cardiothoracic Surgery Cincinnati Children's Hospital Medical Center Cincinnati, OH 45244

Department of Surgery

University of Cincinnati

Cincinnati, OH 45221

\section{References}

1. Carotti A, Emma F, Picca S, Iannace E, Albanese SB, Grigioni M, et al. Inflammatory response to cardiac bypass in ewe fetuses: effects of steroid administration or continuous hemodiafiltration. $J$ Thorac Cardiovasc Surg. 203;126:1839-50.

2. Rosenfeld CR. Consideration of the uteroplacental circulation in intrauterine growth. Semin Perinatol. 1984;8:42-51.

3. Byrne GC, Perry YS, Winter JS. Kinetic analysis of adrenal 3 beta-hydroxysteroid dehydrogenase activity during human development. J Clin Endocrinol Metab. 1985;60: 934-9.

4. Koong LJ, Garrett WN, Rattray PV. A description of the dynamics of fetal growth in sheep. J Anim Sci. 1975;41:1065-8.

5. O'Rahilly R. Early human development and the chief sources of information on staged human embryos. Eur J Obstet Gynecol Reprod Biol. 1979;9:273-80.

doi:10.1016/j.jtcvs.2004.08.033

\section{Reply to the Editor:}

We appreciate the comments of Drs Sedgwick and Eghtesady.

Indeed, the increase in uteroplacental blood flow during the course of pregnancy initially reflects placental development and thereafter vasodilation of the spiral arteries, which increases perfusion of the intravillous space. The increase in uterine blood flow after 110 days in sheep $(75 \%$ of the gestation), which is associated with a 3 -fold increase in fetal weight, is related to vasodilation of the spiral arteries and has been shown to be proportionate to the increase in wet weight of the uterus and its metabolically active tissues, including the fetus, the membranes, and the placenta. ${ }^{1}$

When performing experiments, investigators should always try to choose experimental settings that are the closest to the human model that they are trying to reproduce, bearing in mind, however, that no model will ever correspond exactly to the human condition. This is particularly true when the experimental setting involves pregnancies, which depend on a wide number of factors, including genetic, hormonal, and anatomic factors, both on the maternal and fetal side. As such, we welcome the formula proposed by Drs Sedgwick and Eghtesady but would caution against a rigid application.

Uterine blood flow, for example, has probably little effect in fetal cardiac bypass experiments because the pump provides perfusion only to the fetoplacental unit and not to the maternal uteroplacental compartment. Therefore, endometrial-myometrial blood flow changes beyond 110 days of pregnancy are not likely to significantly influence fetal cardiac bypass.

The increase in fetoplacental blood flow during the last third of pregnancy reflects primarily vascular growth and, to a lesser extent, vasodilation. This generates a fairly stable fetal umbilical blood flow by the end of pregnancy of approximately $200 \mathrm{~mL}$. $\mathrm{kg}^{-1} \cdot \min ^{-1}$ in most studied species. On the other hand, placental weight during ovine pregnancy is relatively stable after the middle third of gestation. ${ }^{2}$ Taken together, these observations indicate that the increase in fetoplacental blood flow during the last third of the gestation is proportionate to the increase of the fetal weight. Therefore, planning of the pump perfusion rate on the basis of the fetal weight as predicted by fetal biometry ${ }^{3}$ at $300 \mathrm{~mL}$. $\mathrm{kg}^{-1} \cdot \min ^{-1}\left(100 \mathrm{~mL} \cdot \mathrm{kg}^{-1} \cdot \min ^{-1}\right.$ fetal perfusion rate $+200 \mathrm{~mL} \cdot \mathrm{kg}^{-1} \cdot \mathrm{min}^{-1}$ placental perfusion rate) is likely to be appropriate during both the middle and the last third of the pregnancy.

Beyond all these considerations, our choice of using near-term fetal sheep originated primarily from the general consensus in the literature of using animals at this stage of pregnancy, which also allows us to perform operations on larger fetuses. The suggestion of lowering the gestational age of future fetal experiments at 83 to 112 days of pregnancy in sheep is well accepted, but its benefits will need to be proved experimentally.

$$
\begin{array}{r}
\text { Adriano Carotti, } M D^{a} \\
\text { Francesco Emma, MD } \\
\text { Department of Pediatric Cardiology and } \\
\text { Cardiac Surgery } \\
\text { Department of Nephrology and Dialysis }{ }^{b} \\
\text { Ospedale Bambino Gesú } \\
\text { Rome, Italy }
\end{array}
$$

\section{References}

1. Rosenfeld CR. Changes in uterine blood flow during pregnancy. In: Rosenfeld CR, editor. The uterine circulation. Ithaca (NY): Perinatology Press; 1989. p. 135-58.

2. Rosenfeld CR. Regulation of the placental circulation. In: Polin RA, Fox WW, editors. Fetal and neonatal physiology. Philadelphia: Saunders; 1992. p. 56-62.

3. Chervenak FA, Skupski DW, Romero R, Myers MK, Smith-Levitin M, Rosenwaks $\mathrm{Z}$, et al. How accurate is fetal biometry in the assessment of fetal age? Am J Obstet Gynecol. 1998;178:678-87.

doi:10.1016/j.jtcvs.2004.08.034

\section{Separate or composite graft replacement for diseases of both the aortic valve and the ascending aorta To the Editor:}

With great interest, we read an excellent article entitled "Clinical outcomes after separate and composite replacement of the aortic valve and ascending aorta," in the August 2004 issue of the Journal. ${ }^{1}$ Sioris and associates reported the differences between aortic root replacement and aortic valve replacement combined with supracoronary replacement of the ascending aorta (separate grafting). They concluded that separate grafting and the Bentall operation provide comparable long-term results and that no patient required reoperation for aortic root aneurysm after separate grafting in patients with aortic valve disease associated with normal or mildly dilated aortic sinuses or a dilated ascending aorta. Their study consisted of a large number of patients (587 patients), and their mean follow-up was $4.6 \pm 3.1$ years.

We have a patient who required aortic root replacement because of dilatation of the residual sinuses of Valsalva 10 years after separate grafting. ${ }^{2}$ The patient had undergone the initial operation for type A 